\title{
Trends in sexual behaviours and infections among young people in the United States
}

\section{A E Biddlecom}

\section{Correspondence to:}

Dr A E Biddlecom, The

Alan Guttmacher Institute,

120 Wall Street, $21 \mathrm{st}$

Floor, New York, NY

10005, USA;

abiddlecom@guttmacher.

org

Accepted for publication 19 July 2004
Objectives: To describe trends over time in sexual behaviour, condom use, and sexually transmitted infections among female and male adolescents in the United States.

Methods: A review was carried out of published studies using data from six surveys since the 1970s on sexual behaviour and surveillance data on sexually transmitted infections.

Results: The proportion of adolescents who have ever had sexual intercourse increased for females and males through the 1980s and then declined for males through the 1990s. Some survey data showed that the level remained unchanged in the 1990s for adolescent females and other sources showed a decline by 2001. Condom use at first sexual intercourse and current condom use have increased over the past two decades for both male and female adolescents. Incidence rates for gonorrhoea and syphilis among adolescents declined over the 1990s and up through 2002, though new diagnoses of HIV/AIDS among adolescents remained relatively constant throughout the 1990s and into the new century.

Conclusion: Although data sources are difficult to compare over time, trends in sexual behaviour, condom use, and sexually transmitted infections among adolescents from different data sources display generally similar directions towards declines in risk behaviours and outcomes, and increases in protective behaviours.
$\mathrm{T}$ rend data on the sexual behaviours and sexual health of young people are crucial for a number of reasons: (1) to assess adolescents' changing behaviours and needs for health information and services; (2) to diagnose the potential for spread of disease; (3) to understand which factors affect adolescent sexual behaviour and whether these effects are changing over time; (4) to inform public policy and the design of public health interventions, and (5) to evaluate the effectiveness of public health interventions. One of the 10 leading national health objectives set by the United States for $2010^{1}$ is to increase responsible sexual behaviour among adolescents (measured as the proportion of teenagers who abstain from sexual intercourse or who use condoms if they are sexually active).

Levels of teenage sexual activity across developed countries are generally similar, but, despite some declines from the 1980s to the 1990s, the United States (US) continues to stand out with much higher rates of unintended pregnancy, abortion, and sexually transmitted infections (STIs) than most other developed countries. ${ }^{2}{ }^{3}$ While these comparisons and the absolute levels themselves make clear the need for public health interventions aimed at adolescent sexual and reproductive health, young people's sexual behaviour is a politically charged issue in the United States, which has, as a result, often affected data collection efforts. ${ }^{4}{ }^{5}$

The purpose of this paper is to describe trends in sexual behaviour (sexual intercourse and other genital sexual activity), condom use, and STIs among adolescents in the US and to assess the robustness of the evidence of trends in these behaviours and outcomes. The paper draws on surveillance data on STIs and on published studies that analyse data on sexual behaviour from six surveys since the 1970s. The data sources differ by mode of administration, sample population, and other dimensions, but a key question is whether the evidence of aggregate trend estimates is consistent across data sources. The characteristics of major data sources in the US are first described, followed by trends in young people's sexual behaviours, condom use, and levels of STIs. Challenges to collecting comparable and accurate trend data in the US are discussed at the conclusion of the paper.

\section{METHODS}

The first key issue for assessing trends in behaviours and infections is whether measurement is comparable over time. National surveys have been conducted in different years and with different frequency. For example, the National Survey of Adolescent Males (NSAM) was conducted in 1988, 1990-91, and 1995, and the Youth Risk Behavior Survey (YRBS) has been conducted biennially since 1991. Thus the time periods in which change is observed are not equivalent. A second key issue is that survey characteristics vary by sample population (household $v$ school based; single sex $v$ both males and females), mode of questionnaire administration (interviewer administered $v$ self-administered), and question wording, all of which can affect the comparability of measures across surveys. A third key issue is change in external factors that may influence reporting bias in sensitive behaviours; what may have been a taboo to admit to in the 1950s may be normal to talk about in the 1990s. To summarise, changes over time in reported levels of sensitive behaviours could be due to real change in the behaviour or changes in measurement or changes in reporting quality over time.

The six main nationally representative surveys in the US on adolescent sexual behaviour are listed in table 1. National survey data on young women's sexual behaviour became available in 1971 and data for young men were available beginning in 1979. All survey data used by the studies cited in this article were collected either in person by an interviewer or were self-administered. Self-administered questionnaires_via paper and pencil or audio computer assisted

Abbreviations: ACASI, audio computer assisted self-interview; NHANES, National Health and Nutrition Examination Survey; NSAM, National Survey of Adolescent Males; NSFG, National Survey of Family Growth; YRBS, Youth Risk Behavior Survey. 
Table 1 Key sources of survey data on the sexual behaviour of young persons in the United States

\begin{tabular}{|c|c|c|c|c|c|}
\hline \multirow[b]{2}{*}{ Survey and website } & \multirow[b]{2}{*}{ Survey years } & \multirow[b]{2}{*}{ Survey type/mode } & \multicolumn{3}{|c|}{ Sample population characteristics } \\
\hline & & & Sex & $\begin{array}{l}\text { School/home } \\
\text { based }\end{array}$ & Age/grade \\
\hline $\begin{array}{l}\text { 1. National Survey of Young Women (NSYW); } \\
\text { http://www.socio.com/srch/summary/daappp/dap01.htm }\end{array}$ & $\begin{array}{l}\text { 1971, 1976, } \\
1979\end{array}$ & $\begin{array}{l}\text { Cross sectional } \\
\text { IA, SA, PP }\end{array}$ & $\mathrm{F}$ & $\begin{array}{l}\text { Household based } \\
\text { in urban areas }\end{array}$ & $15-19$ years \\
\hline $\begin{array}{l}2 \text { National Survey of Family Growth (NSFG); } \\
\text { http://www.cdc.gov/nchs/nsfg.htm }\end{array}$ & $\begin{array}{l}1982,1988, \\
1995, \\
2002-2003\end{array}$ & $\begin{array}{l}\text { Cross sectional IA, } \\
\text { SA, PP (82-88); } \\
\text { CAPI, ACASI }(95,02-03\end{array}$ & $\begin{array}{l}\mathrm{F} ; \mathrm{M} \\
(02-03)\end{array}$ & Household based & $15-44$ years \\
\hline $\begin{array}{l}\text { 3. National Survey of Young Men (NSYM); } \\
\text { http://www. socio.com/srch/summary/daappp/dap45.htm }\end{array}$ & 1979 & $\begin{array}{l}\text { Cross-sectional } \\
\text { IA, SA, PP }\end{array}$ & M & $\begin{array}{l}\text { Household based } \\
\text { in urban areas }\end{array}$ & $17-21$ years \\
\hline $\begin{array}{l}\text { 4. National Survey of Adolescent Males (NSAM); } \\
\text { http://www.nichd.nih.gov/about/cpr/dbs/res_national3.htm }\end{array}$ & $\begin{array}{l}1988,1990-1, \\
1995\end{array}$ & $\begin{array}{l}\text { Panel, new sample (95); } \\
\text { IA, SA, PP (88, 90-91); } \\
\text { IA, SA, PP, ACASI (95) }\end{array}$ & M & Household based & $15-19$ years \\
\hline $\begin{array}{l}\text { 5. Youth Risk Behavior Survey (YRBS); } \\
\text { http://www.cdc.gov/nccdphp/dash/yrbs/index.htm }\end{array}$ & $\begin{array}{l}\text { 1991-present, } \\
\text { biennial }\end{array}$ & $\begin{array}{l}\text { Cross sectional } \\
\text { SA, PP }\end{array}$ & $\begin{array}{l}F \\
M\end{array}$ & School based & Grades 9-12 \\
\hline $\begin{array}{l}\text { 6. National Longitudinal Study of Adolescent Health } \\
\text { (Add Health); http://www.cpc.unc.edu/projects/addhealth/ }\end{array}$ & $\begin{array}{l}1994-5,1996 \\
2001-02\end{array}$ & $\begin{array}{l}\text { Panel } \\
\text { IA, SA, PP, CAPI, ACASI }\end{array}$ & $\begin{array}{l}F \\
M\end{array}$ & School based & Grades 7-12 \\
\hline
\end{tabular}

IA, interviewer administered; SA, self-administered; PP, paper and pencil questionnaire; CAPI, computer assisted personal interview (administered by an interviewer); ACASI, audio computer assisted self-interview (self-administered).

self-interviews (ACASI) - are either the main mode of survey administration (as in the YRBS) or comprise one part of a survey interview (as in the 1995 National Survey of Adolescent Males and the 1995 National Survey of Family Growth).

Trends in adolescent sexual behaviours from the published studies reviewed for this paper draw on these six data sources. Selected findings from other surveys not listed in table 1 (such as the National Survey of Youth) are noted in the text. The measures of sexual behaviour examined from these published studies are constructed in different ways and the sample populations are both population based and school based. Although these differences make it difficult to draw comparisons at any one point in time, evaluating the consistency of the trend evidence can shed light on robustness of the trends as well as the value of self-reports of sexual behaviour.

\section{RESULTS}

\section{Sexual intercourse}

From the 1930s to the end of the 1980s, the proportion of adolescents in the US who ever had premarital sexual intercourse increased..$^{6-10}$ Using retrospective reports of age at first sex for women by birth cohort, Turner et al found that the percentage of women who had premarital sexual intercourse before the age of 15 years rose from less than $2 \%$ of women born at the start of the 20th century, to $4 \%$ for women born in 1944-49, to $12 \%$ of women born in 1968-73. There was also a marked increase in premarital sex by age 18 years, from less than $10 \%$ for the cohort born at the start of the 20th century to over $50 \%$ for the cohort born 1968-73.

Repeated cross sectional surveys in the 1970s of 15-19 year old women living in metropolitan areas showed that the proportion who had premarital sex increased from 30\% in 1971 to $43 \%$ in 1976 to $50 \%$ in $1979 .{ }^{10}$ Results from the $1982-$ 95 National Survey of Family Growth (NSFG) show that the proportion of all 15-19 year old women, not just those residing in metropolitan areas, who ever had sexual intercourse rose from $47 \%$ in 1982 to $53 \%$ in 1988 and remained relatively unchanged at 52\% in 1995 (see table 2). While the proportion of young women who ever experienced sexual intercourse was stable from 1988 to 1995, there was a significant increase in those who had sex at a very early age (before age 15): from $11 \%$ in 1988 to $19 \%$ in $1995 .{ }^{11}$

A similar increase through the 1980s and levelling off in the early 1990s in the proportion who ever had sexual intercourse was observed among young men. Ku et al ${ }^{12}$ show that the percentage of 17-19 year old never-married males (living in metropolitan areas) - the sample population of the first survey of young men in 1979-who ever had sexual intercourse increased significantly from $66 \%$ in 1979 to $76 \%$ in 1988. Results from the National Survey of Adolescent Males for all males aged 15-19 years indicate that the proportion who ever had sexual intercourse significantly declined from $60 \%$ in 1988 to $55 \%$ in $1995 .{ }^{11}$ Unlike the increase observed for 15-19 year old females in the NSFG, the percentage of 15-19 year old males who had had sexual intercourse at an early age remained unchanged from 1988 to 1995 (21\% had had sex by age 15). ${ }^{11}$

Santelli et al compared trends in sexual behaviours of adolescents in the United States across four different surveys over the 1980s and 1990s for 15-17 year olds who were attending grades 9-12. The analytic sample was based on criteria common to all four survey sample populations: age and enrolment in high school. Because sexual behaviours vary by age and school enrolment status, a common analytic sample helped ensure better comparability of measures across surveys and over time. The proportion of male high school students aged 15-17 who ever had sex declined by about 8-9 percentage points from 1988 to 1997 in the YRBS and NSAM survey data, but there was no significant decline for female students for this time period in either the YRBS (1991-97) or the NSFG data (1988-95). ${ }^{7}$ Extending analysis of YRBS data from 1991 to 2001 (and without age restrictions on the sample as above), another study showed a statistically significant decrease in the percentage of high school students who ever had sexual intercourse from 1991 to 2001 : $51 \%$ of female students and $57 \%$ of male students in 1991 were sexually experienced compared with $43 \%$ of female students and $49 \%$ of male students in 2001. ${ }^{13}$ The trend evidence shows a decline in sexual experience for males between 1988 and 2001, no change for females from 1988 to 1995, and a decline for females by 2001. However, the difference in point prevalence estimates can be large. For example, the percentage of 15-17 year old females in high school in 1995 who ever had sexual intercourse was $37 \%$ in the NSFG, $45 \%$ in Add Health, and 52\% in the YRBS. ${ }^{7}$ Although the characteristics of the analytical samples are similar, the differences could be explained by a number of other survey characteristics such as differences in place of interview (the NSFG is conducted in the respondent's home by an interviewer whereas the YRBS is a completely self-administered survey in the respondent's school), response rates, or the location of sensitive questions within the questionnaire. Despite the point prevalence differences, the consistency of the aggregate trend evidence is high across the different surveys. 


\begin{tabular}{|c|c|c|c|c|c|c|c|c|c|}
\hline \multirow[b]{2}{*}{ Outcome (\%) } & \multirow[b]{2}{*}{ Surveys } & \multicolumn{8}{|c|}{ Percentage in survey year } \\
\hline & & 1979 & 1988 & 1991 & 1995 & 1997 & 1999 & 2001 & 2003 \\
\hline \multicolumn{10}{|l|}{ Males } \\
\hline $\begin{array}{l}\text { Ever had sexual intercourse } \\
\text { (17-19 years; urban) }\end{array}$ & $\begin{array}{l}\text { NYSM, } \\
\text { NSAM }\end{array}$ & 65.7 & 75.5 & & 68.2 & & & & \\
\hline $\begin{array}{l}\text { Ever had sexual intercourse } \\
\text { (15-19 years; never married) }\end{array}$ & NSAM & & 60.4 & & 55.2 & & & & \\
\hline $\begin{array}{l}\text { Ever had sexual intercourse } \\
\text { (15-17 years; high school) }\end{array}$ & NSAM & & 49.5 & & 41.3 & & & & \\
\hline $\begin{array}{l}\text { Ever had sexual intercourse } \\
\text { (15-17 years; high school) }\end{array}$ & \multicolumn{2}{|c|}{ Add Health } & & & 45.0 & & & & \\
\hline $\begin{array}{l}\text { Ever had sexual intercourse } \\
\text { (grades 9-12) }\end{array}$ & \multicolumn{2}{|l|}{ YRBS } & & 57.4 & 54.0 & 48.8 & 52.2 & 48.5 & 48.0 \\
\hline $\begin{array}{l}\text { Used condoms at last sex } \\
\text { (15-19 years) (among those } \\
\text { currently sexually active) }\end{array}$ & \multicolumn{2}{|l|}{ NSAM } & 53.3 & & 63.9 & & & & \\
\hline $\begin{array}{l}\text { Used condoms at last sex } \\
\text { (grades 9-12) (among those } \\
\text { currently sexually active) }\end{array}$ & \multicolumn{2}{|l|}{ YRBS } & & 54.5 & 60.5 & 62.5 & 65.5 & 65.1 & 68.8 \\
\hline \multicolumn{10}{|l|}{ Females } \\
\hline $\begin{array}{l}\text { Ever had premarital sex } \\
\text { (15-19 years) }\end{array}$ & NSYW & 49.8 & & & & & & & \\
\hline $\begin{array}{l}\text { Ever had sexual intercourse } \\
\text { (15-19 years) }\end{array}$ & NSFG & & 52.6 & & 51.5 & & & & \\
\hline $\begin{array}{l}\text { Ever had sexual intercourse } \\
\text { (15-17 years; high school) }\end{array}$ & NSFG & & 34.3 & & 36.5 & & & & \\
\hline $\begin{array}{l}\text { Ever had sexual intercourse } \\
\text { (15-17 years; high school) }\end{array}$ & \multicolumn{2}{|c|}{ Add Health } & & & 44.6 & & & & \\
\hline $\begin{array}{l}\text { Ever had sexual intercourse } \\
\text { (grades 9-12) }\end{array}$ & \multicolumn{2}{|l|}{ YRBS } & & 50.8 & 52.1 & 47.7 & 47.7 & 42.9 & 45.3 \\
\hline $\begin{array}{l}\text { Used condoms at last sex } \\
\text { (15-19 years) (among those } \\
\text { currently sexually active) }\end{array}$ & \multicolumn{2}{|l|}{ NSFG } & 31.3 & & 38.2 & & & & \\
\hline $\begin{array}{l}\text { Used condoms at last sex } \\
\text { (grades 9-12) (among those } \\
\text { currently sexually active) }\end{array}$ & YRBS & & & 38.0 & 48.6 & 50.8 & 50.7 & 51.3 & 57.4 \\
\hline
\end{tabular}

Current sexual activity and the frequency of sexual activity reflect other important aspects of adolescent sexual behaviour apart from ever having experienced intercourse and age at the first experience. However, measures of current sexual activity and frequency vary by the time period used and the questions used to construct the measure. Looking at the period 1979-95, Ku et al ${ }^{12}$ found that current sexual activity among young metropolitan men was stable from 1979 to 1988 and then declined from 1988 to 1995: the percentage of all 17-19 year old never-married males (living in metropolitan areas) who had had sexual intercourse in the four weeks before the survey rose from $40 \%$ in 1979 to $45 \%$ in 1988 (though not a statistically significant difference) and then declined to 39\% in 1995 (a statistically significant difference from 1988). Data for all adolescents—not just those residing in metropolitan areas-show that the percentage of all nevermarried 15-19 year olds who had sexual intercourse in the three months before the survey declined significantly for males $(43 \%$ in $1988 ; 38 \%$ in 1995$)$ and remained statistically unchanged from 1988 to 1995 for females (41\% in 1988; 38\% in 1995). ${ }^{11}$ The same stability in levels of current sexual activity was observed for all adolescent females (both everand never-married) in an analysis of NSFG data from 198295. ${ }^{8}$ Among high school students, the prevalence of current sexual activity did not change significantly between 1991 and 2001 (current sexual activity defined as having had sexual intercourse during the three months preceding the survey), fluctuating over the period between $33 \%$ and $40 \%$ of female students and $33 \%$ and $38 \%$ of male students. ${ }^{13}$ The same relative stability in levels of current sexual activity was observed with data from the NSFG and NSAM from 1988-95 for 15-17 year old high school students. ${ }^{7}$
In addition to different time periods, measures of the frequency of sexual intercourse are further complicated by how the information was gathered. Data could be from responses to a specific question about the number of acts of sexual intercourse in the last 12 months (as in the 1979 National Survey of Young Men), questions about the number of acts of sexual intercourse with each recent sex partner, asked partner by partner (as in the 1988 and 1995 NSAM), or from calendar data where the respondent indicates for each month whether or not she had sexual intercourse (as in the 1995 NSFG).

Among adolescent females, the mean number of months in which sexually experienced 15-19 year olds had sexual intercourse in the 12 months before the survey decreased significantly from 9.1 months in 1982 to 8.6 months in 1988 and remained unchanged in $1995 .{ }^{8}$ This pattern suggests that while more adolescent females became sexually experienced during the 1980s, their sexual activity was more sporadic.

The average number of acts of sexual intercourse in the 12 months before the survey among all never-married males aged 17-19 years was statistically unchanged from an average of 14 acts in 1979 and 17 acts in 1988, but then increased significantly to 21 acts on average in $1995 .{ }^{12}$ Focusing only on males who were sexually active, another study of the same data found that the average number of acts of sexual intercourse in the last four weeks significantly declined from 4.6 in 1979 to 3.0 in $1988 .{ }^{14}$ While the proportion of males and females with any sexual experience increased during the 1980s, the inconsistent changes over time observed for the same period in the different measures of frequency of sex provide a different perspective. These divergent trends in sexual behaviour underscore the need for 
measures of multiple dimensions of sexual behaviour over time. An increase along one dimension, such as the proportion initiating sexual activity, does not necessarily lead to an increase along another dimension, such as an increase in the frequency of sexual intercourse or an increase in the proportion that are currently sexually active.

Having multiple sex partners (lifetime or over a recent time period) is often used as a proxy indicator for heightened risk of STIs, especially HIV/AIDS. Again, the measures and sample populations vary over time, but trends since 1979 show no increase in the number of sex partners among adolescents. Among sexually active 17-19 year old males living in metropolitan areas-the sample population in the 1979 survey-the average number of sex partners since first intercourse declined from 7.3 in 1979 to 6.0 in 1988 and the average number of partners in the last four weeks also declined from 1.0 in 1979 to 0.7 in $1988 .{ }^{14}$ Trends since 1988 for sexually experienced male students (age 15-17 years) show no significant change from 1988 to 1995 in the proportion who had two or more partners in the past three months or for those who had four or more lifetime partners. ${ }^{7}$ From 1991 to 2001, YRBS data for all male high school students show a decline in the proportion who had four or more lifetime partners, from $23 \%$ in 1991 to $17 \%$ in $2001 .^{13}$ Trend data for female students show no significant changes from 1988 to 2001 in multiple sex partners. ${ }^{73}$

\section{Condom use}

Consistent and correct condom use plays a critical role in preventing the spread of STIs as well as unintended pregnancy. The measure most commonly documented over time is condom use at first sexual intercourse and last sexual intercourse. Condom use at first sexual intercourse among 15-19 year old sexually experienced women doubled from $23 \%$ to $47 \%$ between 1982 and $1988 .{ }^{15}$ From 1988-95, the proportion of sexually active females and males who used condoms at first sex significantly increased from $50 \%$ to $70 \%$ for females and from 55\% to $69 \%$ for males. ${ }^{11}$ Condom use at last sex in the three months before the survey also rose substantially, from $31 \%$ in 1988 to $38 \%$ in 1995 among adolescent females and from 53\% in 1988 to $64 \%$ in 1995 among adolescent males. ${ }^{11}$ Examining trends in the 1980s and 1990s, Santelli et al observed that condom use among adolescent male students increased significantly from 198897 and also among female students, but only significantly so in the YRBS survey data (1991-97) and not in the NSFG (1988-95). Data from the 1991-2003 YRBS (and without the age restrictions used in the earlier study) show that the proportion of sexually active high school students who used condoms at their last sexual intercourse rose substantially from $38 \%$ to $57 \%$ among females and from $55 \%$ to $69 \%$ among males. ${ }^{13} 16$

The sex differences in reported condom use can be explained, in part, by different ages of sex partners and by question structure and wording. Adolescent females tend to have older sex partners, on average, than do adolescent males. For example, among sexually active, never-married 15-19 year olds in 1995, almost one quarter of females had a sex partner who was four or more years older compared with only $5 \%$ of adolescent males. ${ }^{11}$ Survey data from the early 1990s show that condom use declines as men get older. ${ }^{17}$ Since many more adolescent females than males are asked about condom use with partners who are over 15-19 years old, reports about condom use by adolescent females and males should not be expected to be equivalent. A further explanation is that question structure can lead to higher reporting of condom use among males than females. In the NSFG (which surveyed only females until 2002-2003) and in the YRBS (males and females), a single question was asked about the methods that both the respondent and partner used the last time they had sexual intercourse. In the NSAM (which surveyed only males), a two question format was used-one about method use by the male respondent at last sex, and another question about methods used by his female partner the last time they had sex. The two question format carefully prompts respondents to think about methods used by each partner whereas the single question format possibly allows respondents to pay more attention to methods they themselves used (for example, female respondents would underreport male condom use). Moreover, the specific question wording about condom use for the NSFG and NSAM surveys varied. The NSFG question asked of females was with respect to methods used for "birth control or family planning". The NSAM questions asked of males were with respect to methods used for "contraception-that is, something to prevent pregnancy or sexually transmitted disease", an expanded definition that may have led to more reports of condom use by males.

\section{Sexually transmitted diseases}

Sources of data for sexually transmitted disease (STD) are limited in terms of population coverage and representativeness. The key sources of data in the US are the Centers for Disease Control and Prevention surveillance data, which are summaries of data based on clinic case reports to STD control programmes and health departments in each state as well as testing data from very specific populations (for example, correctional facilities participating in STD prevalence monitoring projects). More than $70 \%$ of syphilis cases are estimated to be reported and $50-70 \%$ of cases are estimated to be reported for gonorrhoea and chlamydia. ${ }^{3}$ A further issue is that surveillance data are non-existent for a number of other STDs such as herpes or genital warts.

As of the mid-1990s, the US had one of the top three highest reported rates of syphilis, gonorrhoea, and chlamydia among 15-19 year olds compared with other developed countries. $^{3}$ The average annual rate of change in STI incidence among adolescents from 1985-90 increased for syphilis, increased for gonorrhoea among males, and decreased for gonorrhoea among females. ${ }^{3}$ The average annual rate of change for the 1990-96 time period decreased for both males and females for syphilis and gonorrhoea incidence rates. $^{3}$ More recent surveillance data from 1998-2002 show a general decrease in syphilis and gonorrhoea rates for 15-19 year old females and males. ${ }^{18}$ Yet almost half of the approximately 18.9 million new cases of STIs in 2000 occurred among 15-24 year olds. ${ }^{19}$

A uniform HIV/AIDS surveillance system did not begin in the US until January 1994 and, although overall cases of AIDS diagnoses increased up until 1992, the number has declined markedly through 1997 and remained unchanged through 1999. ${ }^{20}$ The trend in the rate of young people diagnosed with AIDS has declined from the mid-1990s to 2000: the rate of AIDS cases per 100000 population (by age at diagnosis and year of diagnosis) dropped from 7.6 in 1994 for males aged 13-24 years to 3.8 in 2000 and from 4.3 in 1994 for females aged 13-24 years to 3.1 in 2000. ${ }^{21}$ However, two studies indicate little change in the numbers of new HIV and AIDS cases among young people. In the 25 states which had regulations for the relevant period requiring confidential reporting by name of all persons with confirmed HIV, reports of new HIV diagnoses in 13-21 year olds remained relatively constant from 1994-99, and very little change occurred in the estimated numbers of diagnoses of HIV and AIDS between 1999 and 2002 among 13-24 year olds. ${ }^{20} 22$

Finally, data from two waves of the National Health and Nutrition Examination Survey (NHANES) that included tests for genital herpes show that from the mid-1970s to 
the mid-1990s, the seroprevalence of genital herpes increased among young people (12-19 years old). ${ }^{23}$ The same study found that less than $10 \%$ of all those who were seropositive (including adults) reported a history of genital herpes infection in the survey interview, ${ }^{23}$ thus supporting arguments against reliance on self-report data on STDs. Biomarker data that accompany nationally representative, population based surveys such as NHANES will vastly improve the available information on trends in STDs among the general population of adolescents in the US.

\section{Other genital sexual activity}

While the major focus in data collection efforts has been on vaginal sexual intercourse because of public health interests in adolescent pregnancy and STDs, other genital sexual activity can also put teens at risk for STDs. However, national data on mutual masturbation, oral sex, and anal intercourse among teens is not only limited but politically contentious to collect. ${ }^{24}$ The NSAM did collect data on other genital sexual activity and showed that a substantial proportion of male teenagers engaged in genital sexual activity apart from heterosexual vaginal intercourse: in 1995, 49\% of 15-19 year old never-married males had ever received oral sex from a female and $53 \%$ had ever been masturbated by a female. ${ }^{25}$ Between 1988 and 1995, there was a statistically significant increase in the proportion of adolescent males who had been masturbated by a female (from $40 \%$ to $53 \%$ ) and the proportion receiving oral sex remained unchanged. ${ }^{25}$ The 1988 survey also showed that $1.5 \%$ of $15-19$ year old males reported (in a self-administered paper questionnaire) male to male oral or anal sex. ${ }^{26}$ The 1995 survey data showed much higher levels of male to male sexual contact $(5.5 \%)$ when questions were administered via ACASI compared with a self-administered paper questionnaire (1.5\%). ${ }^{27}$ Trend data for male and female adolescents will be available on these important sexual behaviours with 2002-2003 National Survey of Family Growth ACASI data on mutual masturbation, oral sex (with opposite and same sex partners), anal sex (with opposite and same sex partners), and condom use at last anal sex and last sex of any type (oral, anal, or vaginal).

\section{DISCUSSION}

Trend data for key measures of the sexual behaviour and levels of STIs among adolescents in the US are available from several different data sources. Comparing measures over time is complicated because of differences in mode of administration (self-administered $v$ interviewer-administered; self-administered paper questionnaire $v$ ACASI), sample population (school based $v$ population based versus surveillance data from physician reports), and so on. However, published evidence for the most part is consistent in pointing to similar trends among adolescents in the US on key sexual behaviour and health outcomes.

Firstly, the proportion of adolescent females and males who ever had sexual intercourse increased through the 1980s and then declined for adolescent males through the 1990s. Some survey data showed that the level remained unchanged by the mid-1990s for adolescent females and other sources showed a decline by 2001. Secondly, condom use at first sexual intercourse and current condom use increased over the past two decades as reported by both male and female adolescents. Thirdly, while seroprevalence rates of genital herpes rose through the mid-1990s for adolescents (though more recent data are lacking for the population as a whole), incidence rates for gonorrhoea and syphilis declined over the 1990s and up until 2002, and the number of new diagnoses of HIV/AIDS among adolescents remained relatively constant throughout the 1990s. Overall, change over time has been towards declines in risk behaviours and outcomes and increases in protective behaviours. The general consistency in aggregate trends among sexual behaviours, condom use, and STDs underscores the value of self-report data on sexual behaviour.

Important challenges to the comparability and completeness of trend data on the sexual behaviours of adolescents in the US remain, such as reporting biases over time, infrequency of data collection, small sample sizes, and reliability of self-reports of sensitive behaviours. Addressing reporting bias, particularly changes in reporting bias over time, is one of the most difficult challenges for accurate measurement of change over time. For example, one could speculate that young people are more likely to underreport their own sexual behaviour, especially in school based surveys, given the increase over the 1990s in sex education programmes that focus on abstinence as the only way of preventing pregnancy and STDs. ${ }^{28}$ However, the decline over the 1990s in the percentage of adolescents who ever had sexual intercourse and the increase in condom use among the sexually active parallel declines in several key STDs as well as substantial declines in teenage pregnancy and birth rates in the US over the 1990s. ${ }^{29} 30$

Another challenge to comparable trend data in the US is the infrequency of surveys of adolescents in the US. Comprehensive population based surveys such as the NSFG are costly and have been implemented only about once every seven years. The YRBS is implemented biennially but is not as comprehensive as the NSFG (for example, very little information is collected about sex partners) and the sample is the school based population. One solution that has been implemented in other national surveys, such as NHANES, is to implement a rolling sample, where data are collected on a continuous basis and can be aggregated for analyses. Rolling samples reduce the time gap between survey data because, in essence, the survey is being implemented all the time. However, there still must be a gap of time for sufficient numbers of cases to cumulate for analyses on important subpopulations such as adolescents.

Reliability remains a crucial challenge for examining trends in adolescent sexual behaviour, and the evidence suggests reasons for both concern and hope. One study of the consistency of self-reported age at first intercourse from panel data from the National Youth Survey found that $28 \%$ of adolescents "reported an age at first intercourse inconsistent with the information they provided up to seven years later as young adults". ${ }^{31}$ The direction of inconsistency was equally distributed among those who reported retrospectively a later age at first intercourse than was reported in an annual interview and those who reported an earlier age at first intercourse than was reported in an annual interview. ${ }^{31} \mathrm{~A}$ study of inconsistent reports in Add Health data showed 78\% of adolescents who reported being sexually active at both survey interviews (in 1994-95 and 1996) reported different months or years at first intercourse at each survey interview. ${ }^{32}$ Only $22 \%$ reported the same month and year for first intercourse at each survey interview, and one third reported dates within plus or minus six months. Despite this apparently high level of inconsistent date reporting, the authors found very limited evidence that the inconsistent reports affected estimated ages at first intercourse (using life table techniques) or the gender, ethnicity, and family background effects on the risk of first sex. Reporting differences do, however, significantly change the point prevalence estimates of sexual experience, depending on how inconsistent reports are resolved. Moreover, about one in 10 adolescents could be classified as "reconstructed virgins"- that is, teens who reported ever being sexually active in the first interview and then denied this in the second interview. This percentage is in line with other study estimates from the US where "between $5 \%$ and $12 \%$ of teens 
rescind reports of sexual intercourse" ${ }^{\prime 32}$ Despite individual inconsistency in reports of sexual behaviour, the aggregate trend estimates from different data sources reviewed earlier appear for the most part consistent across sources, and robust.

The data needs for tracking the trends in and explanations for sexual behaviours and related health outcomes have placed a premium on collecting accurate, consistent, and timely information about young people in the US. New survey technologies (such as ACASI) have helped improve the accuracy of self-reported behaviours. Some studies show higher levels of reporting of sensitive behaviours (as in the case of male to male sex by adolescents in the 1995 NSAM) from ACASI interviews compared with paper and pencil selfadministered questionnaires. ${ }^{27}$ Other studies, however, show no significant improvement with ACASI, for example, in reports of male to female sexual contact by adolescent males ${ }^{27}$ or numbers of sex partners by adolescent females. ${ }^{33}$ In addition, some sensitive behaviours are still significantly underreported even with ACASI technology. The case of abortion is a good example of this: one study estimated that even with ACASI data on abortion, women less than 20 years old reported $66 \%$ of actual abortions recorded by abortion providers. ${ }^{34}$ Challenges to obtaining comparable and accurate information over time on the sexual and reproductive behaviour of young people are likely to persist and the need for developing new approaches for improving data collection is likely to continue.

\section{ACKNOWLEDGEMENTS}

Paper prepared for the Workshop on Measurement of Sexual Behaviour in the Era of HIV/AIDS, London School of Hygiene and Tropical Medicine, UK, 4-6 September 2003. The author gratefully acknowledges the comments of Susheela Singh, Jacqueline E Darroch and David Landry, all of the Alan Guttmacher Institute and John Cleland of the London School of Hygiene and Tropical Medicine.

\section{CONTRIBUTION}

A E Biddlecom reviewed the literature and wrote this article.

\section{REFERENCES}

1 United States Department of Health and Human Services. With understanding and improving health and objectives for improving health. Healthy People 2010 (2nd edition). Washington DC: US Government Printing Office, November 2000. Available at http://www. healthypeople.gov/ Document/pdf/volume2/note2vols.pdf (accessed 6 September 2004).

2 Darroch JE, Frost JJ, Singh S, et al. Teenage sexual and reproductive behavior in developed countries: can more progress be made? Occasional Report No 3. New York: The Alan Guttmacher Institute, 2001.

3 Panchaud C, Singh S, Feivelson D, et al. Sexually transmitted diseases among adolescents in developed countries. Fam Plann Perspect 2000;32:24-32, 45

4 Boonstra H. The 'Add Health' survey: origins, purposes and design. The Guttmacher Report 2001;4:10-12.

5 Laumann EO, Michael RT, Gagnon JH. A political history of the National Sex Survey of Adults. Fam Plann Perspect 1994;26:34-8.

6 Alan Guttmacher Institute. Sex and America's teenagers. New York: AGI, 1994.

7 Santelli JS, Lindberg LD, Abma J, et al. Adolescent sexual behavior: estimates and trends from four nationally representative surveys. Fam Plann Perspect 2000;32:156-65, 194.
8 Singh S, Darroch JE. Trends in sexual activity among adolescent American women: 1982-1995. Fam Plann Perspect 1999;31:212-19.

9 Turner CF, Danella RD, Rogers SM. Sexual behavior in the United States, 1930-1990: trends and methodological problems. Sex Transm Dis 1995;22:173-90.

10 Zelnik M, Kantner J. Sexual activity, contraceptive use and pregnancy among metropolitan-area teenagers: 1971-1979. Fam Plann Perspect $1980 ; 12: 230-51$

11 Abma J, Sonenstein F. Sexual activity and contraceptive practices among teenagers in the United States, 1988 and 1995. National Center for Health Services. Vital Health Stat 2001;23:21.

$12 \mathrm{Ku}$ L, Sonenstein FL, Lindberg LD, et al. Understanding changes in sexual activity among young metropolitan men: 1979-1995. Fam Plann Perspect 1998;30:256-62

13 Brener N, Lowry R, Kann L, et al. Trends in sexual risk behaviors among high school students-United States, 1991-2001. Morb Mortal Wkly Rep 2002;51:856-9.

14 Sonenstein FL, Pleck J, Ku L. Levels of sexual activity among adolescent males in the United States. Fam Plann Perspectives 1991;23:162-7.

15 Forrest JD, Singh S. The sexual and reproductive behavior of American women, 1982-1988. Fam Plann Perspect 1990;22:206-14.

16 Centers for Disease Control and Prevention. Surveillance summaries. Morb Mortal Wkly Rep 2004;53(SS-2).

17 Alan Guttmacher Institute. In their own right: Addressing the sexual and reproductive health needs of American Men. New York: AGI, 2002.

18 Centers for Disease Control and Prevention. Sexually transmitted disease surveillance, 2002. Atlanta, GA: US Department of Health and Human Services, September, 2003.

19 Weinstock H, Berman S, Cates Jnr W. Sexually transmitted diseases among American youth: incidence and prevalence estimates 2000. Perspect Sex Reprod Health 2004;36:6-10.

20 Karon JM, Fleming PL, Steketee RW, et al. HIV in the United States at the turn of the century: an epidemic in transition. Am J Public Health 2001:91:1060-8.

21 Centers for Disease Control and Prevention. AIDS Cases in Adolescents and Adults, by Age-United States, 1994-2000. HIV/AIDS Surveillance Supplemental Report 2003;9(No 1)

22 Centers for Disease Control and Prevention. HIV/AIDS Surveillance, 2002 Volume 14. Atlanta, GA: US Department of Health and Human Services, 2003.

23 Fleming DT, McQuillan GM, Johnson RE, et al. Herpes simplex virus type 2 in the United States, 1976 to 1994. N Engl J Med 1997;337:1105-11.

24 Remez L. Oral sex among adolescents: is it sex or is it abstinence? Fam Plann Perspect 2000;32:298-304

25 Gates GJ, Sonenstein FL. Heterosexual genital sexual activity among adolescent males: 1988 and 1995. Fam Plann Perspect 2000;32:295-97, 304.

$26 \mathrm{Ku}$ L, Sonenstein FL, Pleck J. Young men's risk behaviors for HIV infection and sexually transmitted diseases, 1988 through 1991. Am J Public Health 1993;83:1609-15.

27 Turner CF, Ku L, Rogers SM, et al. Adolescent sexual behavior, drug use, and violence: increased reporting with computer survey technology. Science 1998;280:867-73

28 Darroch JE, Landry DJ, Singh S. Changing emphases in sexuality education in US public secondary schools, 1988-1999. Fam Plann Perspect 2000;32:204-11, 265

29 Martin JA, Hamilton BE, Sutton PD, et al. Births: final data for 2002. Natl Vital Stat Rep 2003;52:1-113.

30 Singh S, Darroch JE. Adolescent pregnancy and childbearing: levels and trends in developed countries. Fam Plann Perspect 2000;32:14-23.

31 Lauritsen JL, Swicegood CG. The consistency of self-reported initiation of sexual activity. Fam Plann Perspect 1997;29:215-21.

32 Upchurch DM, Lillard LA, Aneshensel CS, et al. Inconsistencies in reporting the occurrence and timing of first intercourse among adolescents. J Sex Res 2002;39:197-206.

33 Hewitt M. Attitudes toward interview mode and comparability of reporting sexual behavior by personal interview and audio computer-assisted selfinterviewing: analyses of the 1995 National Survey of Family Growth. Sociol Methods Res 2002;31:3-26.

34 Fu H, Darroch JE, Henshaw SK, et al. Measuring the extent of abortion underreporting in the 1995 National Survey of Family Growth. Fam Plann Perspect 1998;30:128-33, 138. 